\title{
Agricultural Products as Raw Materials for Industry*
}

$\mathrm{T}^{\mathrm{o}}$ what extent is agriculture likely in the future to supply the raw materials for industry in addition to food and textiles, her main customers to-day? The answer to this question involves a forecast of both demand and supply: whether the nature of the demands will alter, and whether in meeting them materials or manufacturing methods will change fundamentally. Biochemistry and biotechnology are of great significance for the future of industry, but their value will be judged largely by their power to save expenditure of material and energy. For more than a century, organic chemists have been investigating the atomic structure of the products of organic life, and the new weapons, $\mathrm{X}$-rays and electron diffraction, have been of great service.

Although we still know very little of the mechanism used by Nature in synthesizing these complex substances, it is clear that they are built up on comparatively simple models. Starch, cellulose, hemicellulose, and the pectins appear to be built up from hexose units like glucose, though possibly the primary unit is a triose, like glycerin, containing three carbon atoms, since the units $\mathrm{C}_{6}-\mathrm{C}_{3}$ and $\mathrm{C}_{6}-\mathrm{C}_{3}-\mathrm{C}_{6}$ occur frequently in plant products and the transformation $2 \mathrm{C}_{3}=\mathrm{C}_{6}$ presents no difficulty to Nature. Vegetable oils, fats and waxes are built up of long chains from units of six carbon atoms. Essential oils, resin and rubber are built up from the unit $\mathrm{C}_{5} H_{8}$ with a branched carbon skeleton may be regarded as their parent substance; and from the same unit the plant can construct the terpenes and diterpenes, which have ring structures. The resins are more complex, containing twenty or more atoms, but of similar type.

Proteins are derived from the union of ammonia with carbon-chain units; amino-acids are formed, and their molecules combine to make long chains, like fibroin, the chief protein constituent of natural silk. Long chains similar to these, but folded into rings, are the structural units of the vegetable proteins found in many seeds and tubers. Many alkaloids also can be regarded as built up in the plant through the medium of amino-acids.

The mode of formation of chlorophyll-the key substance in the living world-is obscure; it presents us with the old problem of the hen and

* Based upon the Mather Lecture given by Sir Harold Hartley to the Textile Institute on June 11. the egg, for chlorophyll is essential for the synthesis of carbohydrates, but carbohydrates are required to make chlorophyll. Many natural flavouring substances, for example, eugenol, are built up upon a $\mathrm{C}_{8}-\mathrm{C}_{8}$ skeleton, and this group may be doubled to give constituents of many resins, or with the addition of a $\mathrm{C}_{6}$ group to give the catechins, found in the tannins, and in antho. cyanins, the colouring matter of many plants.

Although Nature synthesizes her complex products from simple units with an ease and certainty that tantalizes the chemist, by elucidating their structure, he has succeeded in synthesizing many of them artificially. Nevertheless Nature has proved to be a cheaper producer than the factory, and is likely to remain so. Many so-called synthetic substances, for example, camphor and ionone (the perfume of violets), are made from vegetable products in which the carbon skeleton has already been formed by the plant, and they are thus the result of chemical processing.

Of greater significance from the point of view of displacement of plant products, is the use of cracked oil gas and natural gas in the United States as starting-points for the manufacture of organic chemicals, and also their production from water gas by catalytic processes, and from calcium carbide made in the electric furnace. Here there is direct competition with the products of the fermentation industry and of wood distillation. Synthetic 'rubber' made from cracked oil gas is another example of this competition. On the other hand, the more detailed knowledge of plant products has led to great developments in their extraction and utilization, for example, the process of fat-hardening, the conversion of molasses into alcohol, glycerin, acetone and other solvents, and the production of furfural from cereal wastes for use as a solvent or as a constituent of plastics. Research has also opened up completely new fields, such as the cellulose products and synthetic resins or plastics, in which agricultural materials like casein, glycerin, soya bean are finding fresh outlets. The possibilities of plastics are great ; at present they are handicapped by high cost, moulding powder costing $£ 75$ to $£ 100$ a ton, and the great pressures required for moulding thermoplastics are expensive to apply to large articles.

The present percentage utilization of agricultural produce in the world is, on a value basis, roughly : food 86-88, textiles $9-8$, and other industries 5-4, so that the consumption by industry is at most only 12-15 per cent of the total production, and 
of this textiles account for about two thirds. On this basis it is estimated that the value of farm, field and forest products used in industry now amounts to about one half that of mineral products, that is, to one third of the whole value of industrial raw materials.

The extent to which agricultural materials may replace minerals and metals will depend on physica] properties and cost. Some plastics are suitable for replacing metals; the use of synthetic resins as adhesives, and the improvements in the manufacture of laminated wood already make it a successful rival to metal in many fields, for the new products possess such advantages as absence of fatigue, high ratio of strength to weight, and resistance to corrosion, whilst the defects of wood due to local weakness are eliminated by the laminated structure. Rubber is also supplanting metal in fields where its elasticity, freedom from abrasion, and value in reducing noise are required. Lam. inated wood is finding many applications in building construction owing to its strength, lightness and low cost ; and the substitution of nitrocellulose and synthetic resins for the older natural resins, and that of the new solvents and plasticizers for the older and cruder materials of the forest-produced type, all in the main involve the use of processed agricultural products. The cost of producing fermentation alcohol from molasses, at $2 d$. a gallon, is estimated at 9d. a gallon; and from maize at $2 s$. a bushel, at $1 s .3 d$. a gallon; but the cost of petrol at the refinery without tax is $3 d$. a gallon; its use to-day as motor fuel is only justifiable on strategic grounds, but when petroleum supplies begin to contract, alcohol will be in a better competitive position. There has been a very great development in the use of new packing materials, made of wood, textiles, cellulose, Cellophane, etc., but mineral oils have been replacing vegetable oils for lubrication, although the total consumption of the latter has not declined.

In the United States, the Farm Chemurgic Council is working strenuously to promote the use of American farm products ; and the Department of Agriculture, with its numerous associations, is admirably equipped for research and development work in this connexion; as also in the wider field of finding new crops like soya bean, tung oil and southern pine, to replace products now imported. Success will depend on the co-operation of industry in providing factories for processing the raw materials and the research necessary to find new and cheaper methods of using them. The utilization of farm wastes and by-products is being investigated; already cull citrus fruits in California are being processed for producing citric acid, citrus oils and pectin, but an economic method for using waste farm cellulose for paper, strawboard, insulating material or packing has yet to be found. Within the last decade, the soya bean has become a major crop in the United States. One ton of it yields about $250 \mathrm{lb}$. of oil and $1,600 \mathrm{lb}$. of meal. The oil is used in edible products and in making paints, enamels, varnishes, linoleum, soap, glycerin and printing inks. The meal is mainly used in foodstuffs, but a good deal goes to the manufacture of protein glues, paper sizes, washable wall-papers, and protein plastics. Mr. Henry Ford has been one of the pioneers of this new crop. It is estimated that the annual output of a million Ford cars involves the consumption of the following quan. tities of farm produce: cotton 89 million $\mathrm{lb}$., maize 500,000 bushels, linseed oil $2 \cdot 4$ million $\mathrm{lb}$, molasses 2.5 million gals., wool 3.2 million $\mathrm{lb}$., leather 1.5 million sq. ft., hogs 20,000 (to supply lard for lubricants, oleic acid and bristles for brushes), mohair $350,000 \mathrm{lb}$., and soya bean oil 2 million $\mathrm{lb}$. (for making enamel).

The discovery of new uses for established crops is well exemplified by research on cotton, which has disclosed the effect of fibre fineness on the strength of cotton yarns. Extensive breeding and selection are showing how to improve this characteristic in American cottons. Strength and durability are needed in cotton used for making bags and bagging, and a fresh outlet here is the development of duplex open and close-mesh fabric bags for packing fruits and vegetables, millions of which have been sold. The use of cotton fabric for reinforcing tarred roads has been investigated, and with seeming success. After the road bed has been levelled and primed with tar, the cotton fabric is laid down and then covered with alternate dressings of asphalt, road metal and chips, which are consolidated with a heavy roller. Strenuous efforts are being made to find new uses for maize. In the Middle West about 7 per cent of the maize crop is processed for industrial purposes, the main products being starch, dextrin, corn syrup, dextrine, corn oil and cake. Finally, sugar or starch derived from second-grade maize or other grain, sugar-beet, and molasses is being converted into industrial solvents.

The energy and skill with which all these investigations are being pursued is beyond praise. The answer to the question posed in the first sentence cannot be definite. The use of carbon compounds is certainly being extended, and perhaps we are approaching a cellulose-plastic age. But the chemist cannot vie with Nature in the cheap production of complex organic molecules: and the future lies in closer association between them. Such a development of the use of agricultural products would be most fortunate in view of the gradual exhaustion of our capital assets, coal and oil. 